\title{
Meso-scale Simulation of Typhoon Generated Storm Surge: Methodology and Shanghai Case Study
}

\author{
Shuyun Dong ${ }^{1}$, Wayne J. Stephenson ${ }^{1}$, Sarah Wakes ${ }^{2}$, Zhongyuan Chen ${ }^{3}$, Jianzhong Ge ${ }^{3}$ \\ $5 \quad{ }^{1}$ Department of Geography, University of Otago, Dunedin, 9016, New Zealand \\ ${ }^{2}$ Centre for Materials Science and Technology, University of Otago, Dunedin, 9016, New Zealand \\ ${ }^{3}$ State Key Laboratory for Estuarine and Coastal Research, East China Normal University, Shanghai, 200062, China \\ Correspondence to: Shuyun Dong (shuyundong23@gmail.com)
}

Abstract. The increasing vulnerability of coastal mega-cities to storm surge inundation means both infrastructure and

10 populations are subject to significant threat. Planning for further urban development should include consideration of the changing circumstances in coastal cities to ensure a sustainable future. A sustainable urban plan relies on well preparedness and prediction of future climate change and multiple natural hazards. In light of these needs for urban planning, this paper develops a general method to simulate typhoon generated storm surge at the meso-scale (1 - $100 \mathrm{~km}$ in length). Meso-scale simulation provides a general approach that could be implemented to fulfil the purpose of planning, and has relatively low

15 requirements for computation time and data, while still providing reasonable accuracy. The case study of Shanghai was chosen to implement this method. The meso-scale simulated results of two historical typhoons not only provides a realistic result at the city level, but is also suitable for implementing a large amount of simulations for future scenario studies. The method is generally applicable to all coastal cities around the world to examine the effect of future climate change on typhoon generated storm surge, even where historical observed data are inadequate or not available.

\section{Introduction}

Rapid urban expansion in coastal mega-cities (cities with populations over 10 million) leads to increased land demand and vulnerability to hazards for significant numbers of people who are economically and socially disadvantaged. It is necessary to be well prepared and plan to ensure a sustainable future for these cities (Timmerman and White, 1997; Jiang et al., 2001; Yeung, 2001). Typhoon generated storm surge is a major hazard for many coastal cities and leads to significant economic

25 losses. Considering the ongoing coastal development and population growth in coastal mega-cities, preparedness and urban planning play a critical role in coastal management and hazard mitigation. Therefore, the increasing vulnerability of coastal mega-cities to storm surge inundation needs be assessed to improve the resilience of these cities (Woodruff et al., 2013; Aerts et al., 2014). 
Nat. Hazards Earth Syst. Sci. Discuss., doi:10.5194/nhess-2017-34, 2017

Manuscript under review for journal Nat. Hazards Earth Syst. Sci.

Discussion started: 15 March 2017

(c) Author(s) 2017. CC-BY 3.0 License.

Many integration models for typhoon and storm surge have been developed and applied in past studies to simulate regional storm surge inundation and analyse its impact (Flather et al., 1998; Lowe et al., 2001; Choi et al., 2003; Jakobsen and Madsen, 2004; Westerink et al., 2008; Zhang et al., 2008; Davis et al., 2010; Elsaesser et al., 2010; Dietrich et al., 2011b; Zheng et al., 2013). In order to achieve highly accurate results, high resolution mesh and data are usually employed in these models, which

5 requires a large amount of computing time and the application of such models are limited to small regions. As suggested by Aerts et al. (2014), existing hydrological models for developing inundation scenario usually need to be adjusted for application at the regional level. A high resolution storm surge model could be too time consuming to be conducted for planning purpose. In this study, the approach developed to model storm surge was to conduct numerical simulations at meso-scale (1 - $100 \mathrm{~km}$ in length), which can then be utilized to compute coastal storm surge under different scenarios. For planning works, a large

10 number of simulations can also be undertaken in this meso-scale modelling to gain a better knowledge of storm surge. The purpose of this paper is to introduce the development of the meso-scale simulation method and using a case study of Shanghai we demonstrate the application of this approach.

\section{Previous Work}

There is a large amount of previous work on the storm surge modelling. Regardless of the models used, previous studies can

15 be divided into three types based on scale of modelling, namely large-, meso-, and small-scale. For large scale storm surge studies, they usually concentrate on simulating storm surge at the national level (>100 km in length). For example, Lowe et al. (2001) developed a storm surge with $35 \mathrm{~km}$ resolution for the North west European continental shelf region, and then analysis the effects of climate change using a regional climate model. Fritz et al. (2010) simulated the storm surge occurring in the Arabian Sea with a spatial resolution range of $1-80 \mathrm{~km}$. Due to the high risk of storm surge, there were also many studies

20 conducted in Louisiana, USA (Westerink et al., 2008; Wamsley et al., 2009; Sheng et al., 2010; Butler et al., 2012) and the Gulf of Mexico area (Dietrich et al., 2011a; Dietrich et al., 2011b; Dietrich et al., 2012). Cheung et al. (2003) also analysed the emergency plan for Hawaii based on storm surge simulations. McInnes et al. (2003) utilized a storm surge model to examine the impact of sea level rise and storm surge on the north-eastern Australian coast. These large-scale storm surge studies normally apply a large spatial resolution, $50-100 \mathrm{~km}$ on average, to allow the simulation to be run smoothly in a large-scale

25 area. It is inevitable that at such large spatial resolution small variations in terms of storm surge level at regional level is lost, making it a less suitable type of model for studying the impact of inundation at a city scale (typically 20-80 km in length).

For meso-scale storm surge modelling, the study area usually focuses on a scale of $1-100 \mathrm{~km}$ in length. Peng et al. (2004) utilized an integrated storm surge and inundation models to simulate storm surge inundation in the Croatan-AlbemarlePamlico Estuary in US. Shepard et al. (2012) demonstrated a method to assessing community vulnerability of the southern

30 shores of Long Island, New York to storm surge. For small-scale of storm surge studies, the focus was at a regional level (1 $1000 \mathrm{~m}$ in length). Taking the study of Funakoshi et al. (2008) as an example, a fine small-scale storm surge model was 
Nat. Hazards Earth Syst. Sci. Discuss., doi:10.5194/nhess-2017-34, 2017

Manuscript under review for journal Nat. Hazards Earth Syst. Sci.

Discussion started: 15 March 2017

(c) Author(s) 2017. CC-BY 3.0 License.
Natural Hazards o

and Earth System

Sciences

Discussions

(c) $\underset{\mathrm{BY}}{\mathrm{B}}$

developed covering the St. Johns River Basin in USA. Xie et al. (2008) developed storm surge modelling to simulate corresponding inundation. Frazier et al. (2010) examined the socioeconomic vulnerability to storm surge in Sarasota County, Florida, USA. Small-scale storm surge studies normally focus on the effect of storm surge at a local level and is commonly used to provide advice for small-scale planning and emergency management.

5 There are a number of storm surge studies conducted in China, and hydrological models for storm surge simulation have been developed. However, these are either at a large or small-scale, which may lead to a loss of spatial resolution in the simulated storm surge results or in huge costs in computation time. This study therefore, utilizes a meso-scale general approach for inundation vulnerability to typhoon storm surge to improve knowledge of inundation vulnerability and to guide future vulnerability mitigation strategies. Moreover, a large amount of simulations is involved in planning works. Therefore, in order

10 to fit this purpose, a meso-scale study for Shanghai as a whole is utilized, these filling the gap between the small and largescales of previous studies.

\section{Methodology}

The objective of this general methodology for simulating typhoon storm surge inundation is to develop an adaptable procedure that allows numerical simulations to be carried out easily in coastal cities around the world. Firstly, the data required in the

15 typhoon and storm surge simulations was assembled, including the observation data from typhoons, tidal constituents, topography, and land use data. Two historical typhoons were selected to develop typhoon profiles and then wind and pressure fields were computed to drive the hydrodynamic storm surge model. Typhoon wind and pressure field was calculated based on historical typhoon profiles. Moreover, tidal observed data was collected to validated hydrodynamic models in the next step. The next step was to implement a multi-nested storm surge model to simulate the generation and propagation of typhoon-

20 driven storm surge model at coastal and regional scales. The historical wind and pressure fields are inputs into the coastal hydrodynamic model along with the tidal constituents as key driving factors to simulate the initial current and wind-induced wave at coastal scale. Then, considering river discharge and coastal protection works, storm surge is simulated using the regional hydrodynamic model with a fine spatial resolution unstructured mesh. Lastly, the flood depth can be extracted from the simulation results in regional hydrodynamic model and overlaid onto the urban digital elevation model, where the flood

25 depth and its spatial extent are displayed on a two-dimension flood map. Specifically, the proposed methodology will be explained in following sections.

\subsection{Assembling Data}

An accurate wind and pressure field has been identified as having an important role in storm surge modelling (Bode and Hardy, 1997). In order to provide wind and pressure field to drive storm surge in hydrodynamic model, historical typhoon data needs 30 to be collected from records. There are various types of typhoon data, such as best track data, observed data, and satellite data. 
Nat. Hazards Earth Syst. Sci. Discuss., doi:10.5194/nhess-2017-34, 2017

Manuscript under review for journal Nat. Hazards Earth Syst. Sci.

Discussion started: 15 March 2017

(c) Author(s) 2017. CC-BY 3.0 License.

Typhoon wind and pressure field are calculated in this framework by applying the parametric model built in MIKE 21 Cyclone Wind Generation tool. Typhoon data required in the simulation then are the typhoon track, the central and neutral air pressure, and the maximum wind speed. This data can usually be found in best track data published by meteorological agencies (Ying et al., 2014) or satellite reanalysis database (Simmons et al., 2007). The development and optimization process of typhoon

5 wind modelling is described in Section 3.3. To pre-process the data for the subsequent modelling, all the historical topography and meteorological data was digitized into appropriate formats, including bathymetry, urban digital elevation model, land use map, and coastal engineering features. In this step, tide constituents will also be prepared in the format that is required in storm surge modelling.

\subsection{Developing a Multi-Nested Storm Surge Coupling Model}

10 Water propagation at the coast is significantly sensitive to surface wind forcing and astronomic tides, especially during typhoon events. In order to provide an accurate wind and pressure fields and tide influence for the coastal and regional circulation, a two-domain, multi-nested Typhoon Storm Surge Model (TSSM) was set up, covering the coastal and regional geographic scales. In this method, MIKE 21 was chosen to simulate typhoon generated storm surge with consideration of river discharge and coastal protection works. As commercial software, MIKE 21 has broad applicability and a low requirement of specialized

15 knowledge. In general, a hydrodynamic model for the coastal area will be set up and calibrated against tide observed data. Then the coastal hydrodynamic storm surge model will be utilized to calculate the corresponding distribution of wave field under the influence of the historical typhoon wind and pressure field. On the basis of this, a regional storm surge model can be built for shallow water to consider wave refraction, diffraction, and transformation in order to calculate storm surge in the research area. After calibration against the measured historical data of storm surge, this multi-nested model can be applied to

20 project the impact of storm surge in the future for the study area.

(1) Grid Model and Resolution

In order to precisely simulate storm surge in any coastal area, a fine grid model with appropriate resolution should be constructed for the coastal terrain and topography. The grid greatly affects the generation, propagation and reflection of the wave, and bottom friction. However, very fine grid resolution usually gives rise to significant increases in the computing time

25 and resource. Thus, a balance between accuracy of numerical simulation and the enormous computing requirement should be achieved in the model. The resolution of the unstructured mesh applied in the coastal hydrodynamic model is recommended to be set in a range of $1 \mathrm{~km}$ at the coastal zone to $10 \mathrm{~km}$ at the open ocean boundary. For the regional hydrodynamic model, the resolution can be more precise with an average of $300 \mathrm{~m}$.

(2) Coastal Hydrodynamic Model 
Nat. Hazards Earth Syst. Sci. Discuss., doi:10.5194/nhess-2017-34, 2017

Manuscript under review for journal Nat. Hazards Earth Syst. Sci.

Discussion started: 15 March 2017

(c) Author(s) 2017. CC-BY 3.0 License.

Wind and pressure fields of the typhoon, together with astronomic tide and waves are the main factors of storm surge that need to be taken into account in simulations (Savioli et al., 2003). Combining the statistical hydrological and meteorological data, a coastal typhoon storm surge model is designed and developed with MIKE software to simulate historical storm surge events, which in turn allows simulation of the hydraulics, waves and related phenomena in the coastal area. This coastal hydrodynamic model with flexible mesh is built up in the MIKE 21 flow model to simulate wind-generated waves and current conditions with respect to pre-processed tide, wind and pressures fields. This coastal typhoon storm surge model will be calibrated under normal circumstances to fit the current tidal conditions firstly, then run for the typhoon storm surge events in the past to ensure the reliability of simulated results. First of all, this coupled model will only run to compute tide parameters during the three days before typhoon activities in the entire region for the purpose of calibrating. Then the model will be run to simulate

10 historical typhoon events and the simulation calibrated with observed data of surge elevation. In addition, computed data of wind speed and direction can be calibrated against satellite data or local measured data.

\section{(3) Regional Hydrodynamic Model}

Based on the computed data from the coastal hydrodynamic, a regional model is developed to simulate the movement of typhoon-inducted surge at a relatively small-scale regional area. Then the regional model can be run for different scenarios, to

15 project the effects of global climate change and land subsidence on the regional storm surge level. This regional hydrodynamic model could provide predicted results under various scenarios to the decision makers of hazard mitigation and emergency evacuation planner. By analysing various future scenarios, a better understanding of the coastal vulnerability can be reached, then appropriate preparedness and mitigation can be made.

\subsection{Storm Surge Inundation Modelling}

20 For large-scale and meso-scale studies, storm surge inundation mapping can be conducted to predict the inundation depth and spatial extent. The approach to inundation mapping can also be utilized for the purpose of further planning which aims to predict the distribution of storm surge inundation, especially in land reclamation planning. Based on the typhoon storm surge simulation results from the regional hydrodynamic model, inundation maps are drawn using ArcGIS. The inundation situation under different scenarios can then be analysed.

\section{3.4 Optimizing Process in Wind Field Simulation by MIKE Software}

In order to analyse the storm surge caused by typhoons, a precise simulation is closely bound up with the accuracy of wind and pressure field specification. It is therefore of considerable significance that a specific, accurate and representative typhoon field is input into the typhoon model. In this study, the wind and pressure field of the typhoon was generated by parametric model in the MIKE 21 Cyclone Wind Generation tool. There are four parametric models built in this tool, namely the Young 
Nat. Hazards Earth Syst. Sci. Discuss., doi:10.5194/nhess-2017-34, 2017

Manuscript under review for journal Nat. Hazards Earth Syst. Sci.

Discussion started: 15 March 2017

(c) Author(s) 2017. CC-BY 3.0 License.

\& Sobey (Young and Sobey, 1981), Holland (Holland, 1980), Holland for double vortex (Harper and Holland, 1999), and Rankine (Rankine, 1872).

Each of these models has been validated and employed in past studies. Through comparison, Holland model has been chosen to simulate the typhoon wind field in Shanghai case study because the adjustability of the Holland parameter $B$ allows the model to be modified to fit the data better.

Most of the parameters in the Holland model can be collected from the typhoon best track dataset of the China Meteorological Administration and the European Centre for Medium-Range Weather Forecasts (ECMWF) (Molteni et al., 1996). The remaining two parameters, the radius of maximum wind $\boldsymbol{R}_{\boldsymbol{m} w}$ and parameter $B$, was calculated by Eq. (1) (Ge et al., 2013) and Eq. (2) (Vickery et al., 2000) respectively.

$10 \quad R_{m w}=\left(7.5757576 \times 10^{-5}\right) \times P_{c}{ }^{2}-0.50560606 \times P_{c}+477.01515$

$B=1.38-0.00184\left|P_{c}-P_{n}\right|+0.00309 R_{m w}$

where $P_{c}$ represents the pressure at the typhoon centre or central pressure, $P_{n}$ is the ambient surroundings' pressure field or neutral pressure.

Although the computed results by the Holland model show that the model is in good agreement with the actual observation, a

15 relative error remains in the computation after typhoon landfall. Compared to the observation data, the computed wind speeds fall rapidly after the typhoon made landfall. After analysing the parametric model results, the ECMWF Dataset will be adopted in this study as the background wind field in order to obtain a better simulation result by adjusting the shape of the typhoon wind field.

In order to improve the quality of typhoon simulated results, a commonly applied approach is to blend with satellite reanalysis database, such as global National Centres for Environmental Prediction and National Centre for Atmospheric Research (NCEP/NCAR) Reanalysis data and ECMWF reanalysis dataset (Dutta et al., 2003; Jia et al., 2011). The ECMWF reanalysis dataset has a better spatial resolution of $0.25^{\circ}$ than NCEP/NCAR $\left(2.5^{\circ}\right.$ ). Therefore, the ECMWF dataset was chosen to be adopted here as the background wind field to achieve a more precise result at the outer area of the radius of maximum wind.

The ECMWF reanalysis dataset is a continually updating dataset with the finest resolution of a $0.25^{\circ} * 0.25^{\circ}$ grid mesh

presented by the European Centre for Medium-Range Weather Forecasts. It has been recording joint data from diverse, advanced, operational, numerical models, representing the state of the Earth's atmosphere, incorporating observations and a numerical weather prediction model four times daily since 1948 (Simmons et al., 2007). As a result of the assimilation of the observational data, the recorded atmospheric circumstances in the ECMWF dataset can be regarded as real (Molteni et al., 1996). Therefore, the ECMWF can provide a precise, nearly real atmospheric background for adjusting the Holland model. 
Nat. Hazards Earth Syst. Sci. Discuss., doi:10.5194/nhess-2017-34, 2017

Manuscript under review for journal Nat. Hazards Earth Syst. Sci.

Discussion started: 15 March 2017

(c) Author(s) 2017. CC-BY 3.0 License.

In order to integrate the strong points of the MIKE software and the ECMWF reanalysis dataset, the MIKE Software Development Kit (SDK) is used here to optimize the simulation results from the MIKE 21 Cyclone Wind Generation Tool. The wind speed $V(\mathrm{r})$ at a distance $r$ from the centre of the typhoon, can be given by Eq. (3):

$V(\boldsymbol{r})=\left\{\begin{array}{cr}V_{M I K E}, & r<\boldsymbol{R}_{m w} \\ V_{E C M W F} & , \boldsymbol{r}>\boldsymbol{R}_{m w} \\ a V_{M I K E}+(1-\boldsymbol{a}) V_{E C M W F}, & \boldsymbol{r}=\boldsymbol{R}_{m w}\end{array}\right.$

5 where $V_{M I K E}$ is the wind speed calculated by the MIKE 21 Cyclone Wind Generation Tool, $V_{E C M W F}$ is the wind speed computed from the ECMWF interpolation results, and $a$ is the weight factor in order to smooth rough edges. An optimized coupled wind and pressure field can be generated by programming in the MIKE SDK based on Eq. (3).

A methodology for simulating typhoon storm surge in coastal cities was described as above, which is applicable to coastal mega-cities around the world. An implementation of the application of simulating typhoon storm surge inundation for Shanghai

10 will presented in Section 4.

\section{Case Studies in Shanghai}

Following the proposed framework for assessing inundation vulnerability to storm surge, a case study of Shanghai is used to examine the application of this proposed approach. Shanghai is one of the fastest economically developing regions in China, a large number of migrants are attracted to the city from throughout the rest of China. Shanghai lies half way point along the

15 China Eastern Coast, the East China Sea being its neighbour to the east and Hangzhou Bay to the south, including Chongming, Changxing, and Hengsha Island (Figure 1). There were 16 major storm surge events in Shanghai from 1905 to 2000; five of them (in 1905, 1933, 1981, 1997, and 2000) have led to severe flooding and billions of yuan in economic damage.

Along the Shanghai coast, land reclamation has grown substantially due to the huge demand for land for further urban development, about $480 \mathrm{~km}^{2}$ land has been claimed in Shanghai from 1954 to 1990 (Shanghai Nongken Chronicles

20 Compilation Committee, 2004). On the one hand, the reclamation land can alleviate the pressure on land that results from the continuous growth of cities in the process of rapid expansion. Most of the newly reclaimed land has been used for agriculture and industry (Shanghai Municipal Planning and Land \& Resources Administration, 2010). The other side of this is that such extensive reclamation activities require long-term, well-developed planning, otherwise they may result in increased vulnerability and even catastrophic damage due to natural hazards.

25 Typhoon Winnie in 1997 and Typhoon Wipha in 2007, are chosen as case studies to simulate typhoon storm surge and assess the vulnerability to typhoon storm surge inundation of differing land use types under sea level rise and land subsidence scenarios. Typhoon Winnie (1997) was an especially large and devastating typhoon. After passing north of Taiwan, Winnie made landfall at the south-east of Shanghai in Wenling, Zhejiang province on 18 August 1997. Its centre was never closer than 
Nat. Hazards Earth Syst. Sci. Discuss., doi:10.5194/nhess-2017-34, 2017

Manuscript under review for journal Nat. Hazards Earth Syst. Sci.

Discussion started: 15 March 2017

(c) Author(s) 2017. CC-BY 3.0 License.

$400 \mathrm{~km}$ from Shanghai. The storm surge caused by Winnie led to extraordinary levels of flooding. Winnie gave rise to 212 deaths, over 1 million people were displaced, and there are 4.1 billion yuan of economic losses (State Oceanic Administration, 1989-2015). A resulting storm surge of up to $6.57 \mathrm{~m}$ was measured at Jinshanzui Station. After landfall, Winnie shifted from the northeast to northwest, giving rise to approximately $37 \mathrm{~km}$ of riverbank overflowing and $70 \mathrm{~km}$ of dike breaches (Zhu et

5 al., 2002). A storm surge with a wave height of approximately $7.9 \mathrm{~m}$ developed in Zhejiang province, then this decreased to around $5.72 \mathrm{~m}$ as it approached the Shanghai area. Typhoon Wipha (2007) was another destructive typhoon which passed near Shanghai and landed in Cangnan, Zhejiang province on 19 September 2007. As a typical turning track typhoon, it passed to the west of Shanghai during landfall. Although the eye of the Wipha did not pass near Shanghai, its outer strong wind and rain bands resulted in severe flooding to Shanghai. Although the recorded highest water level in Shanghai was only $3.39 \mathrm{~m}$ during

10 this typhoon on 19 September 2007, there were 128 roads flooded and over 1 million yuan of direct losses were caused in Shanghai. In addition, almost 300,000 people had to be evacuated by the Shanghai government (State Oceanic Administration, 1989-2015).

Both Winnie and Wipha were categorised as super typhoons by the China Meteorological Administration and caused serious storm surges in Shanghai. These two typhoons affected a wide ranging area, thus their simulation results could provide more information on the vulnerability of different land use types under worse case scenarios. Winnie and Wipha represented the typical turning track typhoon. They developed in the northern Pacific Ocean, and then tracked north-westward to China. After they passed across the East China Sea, they moved north-eastward. As with the majority of typhoons affecting Shanghai, although they did not make landfall directly at Shanghai, they generated high storm surge in Shanghai, $5.72 \mathrm{~m}$ during Winnie and 3.39 m during Wipha. Winnie happened in August 1997 and Wipha in September 2007; both of them occurred during the

20 active time period of typhoon events. In addition, the 10 years' interval between these two typhoons could allow the simulations to reveal how inundation vulnerability of different land use types to typhoon storm surge changed over time.

\subsection{Required Data and Processing}

Data regarding topography and meteorological data from Shanghai in both 1997 and 2007 were collected and processed before simulation. Assimilated wind data were required using best track data from the China Meteorological Administration Tropical

25 Cyclone Data Centre and ECMWF Global Reanalysis Products with a resolution of $0.25^{\circ}$. Both of these two datasets have a 6-hour interval, therefore integrate well with each other in the typhoon model to improve the accuracy of simulated results.

The computational models in this study for storm surge simulation employ an unstructured mesh spacing of $1 \mathrm{~km}$ in the regional area and $100 \mathrm{~km}$ in the open sea area. The topographical data applied in the urban area to generate the flexible mesh was provided by the East China Normal University. The topographical data was extracted from the digital elevation model of

30 Shanghai with a $5 \mathrm{~m}$ spatial resolution. Bathymetry was taken from the ETOPO1 Global Relief Model downloaded from NOAA with a grid resolution of 1 arc-minute. Through validation, ETOPO1 bathymetry data do not meet the requirement of 
Nat. Hazards Earth Syst. Sci. Discuss., doi:10.5194/nhess-2017-34, 2017

Manuscript under review for journal Nat. Hazards Earth Syst. Sci.

Discussion started: 15 March 2017

(c) Author(s) 2017. CC-BY 3.0 License.

the coastal and regional storm surge models with regard to the resolution. The differences between ETOPO1 data and measured data are usually in the range of 5-10 $\mathrm{m}$. Therefore, data provided by the East China Normal University with a spatial resolution of $1 \mathrm{~km}$ were adopted to improve the accuracy of the bathymetry data near shore.

Four gauge stations were utilized here to validate and calibrate the simulated results from the typhoon and storm surge models.

5 Computed wind and storm surge results from numerical models have been calibrated based on observation data at the two gauge stations off the coast of Shanghai, at Daji and Tanxu Stations (Fig. 1).

\subsection{Typhoon Modelling}

In this study, the impacts of typhoon are derived from the wind and pressure fields. Typhoon simulation in this study was conducted using the MIKE 21 Cyclone Wind Generation tool. In order to improve the accuracy of the simulated results, the

10 reanalysis dataset from ECMWF has been applied in MIKE SDK. Details are given in the following sections regarding the setup, calibration, and computed results of Typhoons Winnie and Wipha.

The typhoon model produces an output with a 1-hour interval, including the air pressure, and $\mathrm{U}$ and $\mathrm{V}$ components of wind speed. Afterwards, the simulated results have been passed to the storm surge model to generate wind-induced waves. The dataset used to initialize and, subsequently, simulate wind and pressure field in MIKE 21 was extracted from the best track

15 data published by the CMA Tropical Cyclone Data Centre. The data for model optimization in MIKE SDK were a ECMWF reanalysis dataset with 6-hour intervals and a resolution of $0.25^{\circ} * 0.25^{\circ}$. Here, in this study, the wind and pressure fields were generated with the parametric model of Holland's wind field profile for the area between $30-35^{\circ} \mathrm{N}, 120-130^{\circ} \mathrm{E}$. ETOPO1 data and local measured data were employed to develop a topographical profile of the entire coastal domain.

The Holland parameter $B$ is the most importance parameter to calibrate simulation results. Beside this, the Holland model is

20 also subject to several configuring parameters for geostrophic correction, forward motion asymmetry correction, and wind inflow angle correction. The geostrophic correcting parameter can be implemented as a constant or as varying according to the wind speed at different places. In order to correct the asymmetrical forward movement of a tropical cyclone, a correction factor $\delta_{f m}$ and the maximum angle of cyclone movement are introduced into the model to adjust the wind profile. In the case of Shanghai, $\delta_{f m}$ was set to 1 as recommended in the MIKE 21 manual. The maximum angle was set to $115^{\circ}$ and $150^{\circ}$ as the

25 maximum angles of Winnie's and Wipha's movements, respectively. Observed data from two wind gauge stations (Daji and Tanxu) have been used to calibrate the typhoon model. Results were outputted from the Holland model at $1 \mathrm{hr}$ intervals. After calibration of the model, the computed results have been passed to MIKE SDK, and integrated with ECMWF. 
Nat. Hazards Earth Syst. Sci. Discuss., doi:10.5194/nhess-2017-34, 2017

Manuscript under review for journal Nat. Hazards Earth Syst. Sci.

Discussion started: 15 March 2017

(c) Author(s) 2017. CC-BY 3.0 License.

\subsection{Shanghai Coastal Typhoon Storm Surge Model (SC-TSSM)}

Based on a simulation of two historical typhoons in the typhoon model, the results were input into storm surge models to provide the wind profile. In order to simulate a typhoon generated storm surge on coastal and regional scales, a Shanghai Coastal Typhoon Storm Surge Model (SC-TSSM) was developed here. The SC-TSSM was established to simulate the storm

5 surge in Shanghai provoked by historical Typhoons Winnie and Wipha. In this section, the configuration, validation, and calibration of the SC-TSSM will be described in detail, and the simulated results of a storm surge caused by two selected typhoons will be discussed accordingly. SC-TSSM covers the Shanghai coastal area between latitudes $27-35^{\circ} \mathrm{N}$ and longitudes $120-128^{\circ} \mathrm{E}$ (Fig. 2). This domain has varying resolutions from $1-100 \mathrm{~km}$.

This unstructured-grid high-resolution model has been developed to satisfy the computation requirements during storm surge

10 simulation, within the geographic coverage of the Shanghai sea area. This model system contains both the Shanghai Coastal Typhoon Storm Surge Model (SC-TSSM) and the regional Hengsha Island Typhoon Storm Surge Model (HI-TSSM). Multiple physical factors are included in this model system, such as typhoon events, open ocean currents, astronomical tides, surface waves and freshwater discharge. Surface Water Modelling System (SMS) was applied to generate mesh for this study since it has a more effective grid generation function than MIKE, and it can refine a flexible mesh gradually which cannot be achieved in MIKE.

In this model, the effect of different shapes of the sea wall in the storm surge model is small, therefore the shape of the sea wall was assumed to be trapezoidal. The height of the sea wall along the Shanghai coastline has been set to $6.37 \mathrm{~m}$ relative to mean sea level. The manning number was chosen as the bed resistance factor, and it was set to $80 \mathrm{~m}^{1 / 3} / \mathrm{s}$ for ocean and $32 \mathrm{~m}^{1 / 3} / \mathrm{s}$ for land area. For wind forcing, the input wind profile was generated from the computed results of typhoon model, including

20 air pressure and U/V component of wind velocity that varied in time and domain. Since the Yangtze Estuary is included in the SC-TSSM, the river's discharge should be taken into consideration as a source of freshwater. Based on previous work, the discharge of Yangtze River has been set to $45000 \mathrm{~m}^{3} / \mathrm{s}$ as the mean discharge for the period of July-September (Ge, 2010).

As shown in Fig. 3, the results suggest that the SC-TSSM can simulate the propagation of storm surge satisfactorily. In general, the numerical computation results are in good agreement with the observations, although some sections of the simulation are

25 under-predicted. For example, the differences between computation and observation are in the range of $0.2-0.5 \mathrm{~m}$ from 17 to 19 September 2007.

In the SC-TSSM, the storm surges generated by Winnie and Wipha were simulated. After being calibrated, the typhoon storm surge developed in MIKE proved it was capable of closely agreeing with what was observed. Based on simulation results from MIKE 21, distribution maps of storm surge inundation and inundation depth in Shanghai, during the two case study typhoon 30 events, are presented in Fig. 4. Simulation results of typhoon Winnie and Wipha show both typhoons gave rise to storm surge inundation in Shanghai to a great spatial extent. The distribution of storm surge inundation caused individually by Winnie and 
Nat. Hazards Earth Syst. Sci. Discuss., doi:10.5194/nhess-2017-34, 2017

Manuscript under review for journal Nat. Hazards Earth Syst. Sci.

Discussion started: 15 March 2017

(c) Author(s) 2017. CC-BY 3.0 License.

Wipha was basically the same. There are a few differences in flood depth observed along the coastline and on the east and north coasts of Chongming and Hengsha Islands. The average inundation levels, of the storm surge that occurred during these two typhoons, were $1.78 \mathrm{~m}$ in 1997 (Winnie) and $0.9 \mathrm{~m}$ in 2007 (Wipha) in eastern Shanghai. Generally, the mouth of Yangtze River, Hangzhou Bay, Chongming, and Hengsha Islands, and the river bank along the Dazhi and Huangpu Rivers were the most seriously affected areas during these typhoon storm surge inundations. The inundation depths at these places were usually over $1.0 \mathrm{~m}$.

In China, previous studies of storm surge modelling were usually conducted at large and small scales. Most of these studies emphasized the significance of numerical modelling of storm surge and risk analysis either for the coastline on a large spatial scale or for the local coastal area with fine resolution simulation. For example, Zheng (2010) developed a numerical mode to

10 simulate storm surge under the effects of tide and wind wave for the coast of China. In 2011, Tan et al. (2011) assessed the vulnerability of coast cities in China to storm surge using an indicator system. Yin (2011) also assessed the China coastal area's risk to typhoon storm surge based on the simulated results from large scale storm surge model and a proposed indicator system. Some other studies laid their emphasis on analyse the storm surge at small regional scale area along the Chinese coast (Zhang et al., 2006; Xie, 2010; Xie et al., 2010; Ye, 2011). Therefore, there are a number of storm surge studies conducted in

15 China, and hydrological models for storm surge simulation were developed. However, these are either at a large or small scale, which may lead to the loss of spatial resolution of simulated storm surge results or huge costs in computation times. This mesoscale study here fills the gap between the small and large scales of preview studies.

\section{Discussion}

For typhoon storm surge modelling, this study suggested a meso-scale simulation could be used to compute storm surge inundation and assess the inundation vulnerability of different land use types. There is a large number of studies have been done on storm surge simulation. This study enlarged the body of knowledge on storm surge studies in Shanghai, and also proposed a meso-scale simulation to fit the purpose of coastal planning. Unlike most past studies, a meso-scale study not only meets the spatial requirements of numerical models, but also does not require much cost for computation. Previous studies on the storm surge were usually conducted at national or local levels (Dietrich et al., 2011a; Butler et al., 2012). In China, most of these studies tended to emphasize the significance of numerical modelling of storm surge and risk analysis either for the coastline on a large spatial scale (>100 km in length) (Zheng, 2010; Tan et al., 2011; Yin, 2011) or for the small scale coastal area (1 - 1000m in length) with fine resolution simulation (Zhang et al., 2006; Xie, 2010; Xie et al., 2010; Ye, 2011). The majority of these studies concentrated on three districts in the Shanghai coastal area, namely, the Pudong, Jinshan, and Fengxian Districts (Xie, 2010; Ye, 2011). These studies failed to pay enough attention to the river basins. However, according to the results in this study, the river basins of the Dazhi and Huangpu Rivers are among the most serious impacted areas during 
Nat. Hazards Earth Syst. Sci. Discuss., doi:10.5194/nhess-2017-34, 2017

Manuscript under review for journal Nat. Hazards Earth Syst. Sci.

Discussion started: 15 March 2017

(c) Author(s) 2017. CC-BY 3.0 License.

typhoons Winnie and Wipha. Meso-scale (1 - $100 \mathrm{~km}$ in length) studies on storm surge have not been conducted in Shanghai, and the meso-scale framework in this study fills the gap.

Large and small-scale simulations do each have their own advantages. For example, large-scale simulations require low consumption of computation resources and time. Large-scale studies therefore could be applied on a national scale to analyse

5 typhoon storm surge impacts, to simulate typhoon and storm surge changes over time, and to provide necessary data to propose general plans for hazard mitigation. Small-scale simulations usually involve fine spatial resolutions, ranging from $5 \mathrm{~m}$ to 100 $\mathrm{m}$, in order to capture subtle changes of the flood waters. Nonetheless, neither large nor small-scale simulations always fit for coastal planning purposes. Large-scale simulation is not suitable for local planning because of its rough spatial resolution that cannot reflect the detailed distribution of storm surge inundation. Although numerical simulation, in the context of coastal

10 planning, requires a huge number of accurate and detailed computation results at the regional level, high spatial resolution at the local scale will have high costs in terms of computation resource and lengthy time consumption. For example, a smallscale model with a fine spatial resolution mesh of $100 \mathrm{~m}-1 \mathrm{~km}$ has been initially used in this study, covering only the estuary and coastal area. It required over 600 hours to run one simulation on a computer with 16G RAM, 500G SSD, quad-core Intel Core i5 processors. Compared to the 600 hours of computation time by small scale model, the multi-nested meso-scale model

15 only required about 30 hours to run a single simulation with a reasonable accuracy where required. Meso-scale studies could not only fulfil the requirements for simulation accuracy, but also take less time and computation consumption. They are more suitable for use when a large number of simulations are to be projected over a long time scale. By implementing this mesoscale model, this study would like to draw back the focus of storm surge simulation to an appropriate medium scale to fit the research purpose.

20 Moreover, previous studies claimed that commercial software cannot achieve a precise result (Strauss et al., 2007; Lin and Fissel, 2014). However, the calibration between the modelled results and observed data demonstrate that MIKE software shows good agreement with data accumulated from observation. It was clear that MIKE could be applied in a meso-scale study to produce a good simulation. This study also provided more specific results suggesting the Huangpu and Dazhi Rivers are among the most serious of the flooded areas and should be paid more attention. Those areas were normally excluded or ignored in

25 previous studies (Xie, 2010; Ye, 2011). Computed results showed that the river banks along the Huangpu and Dazhi Rivers experienced high vulnerability to typhoon storm surge inundation during typhoons Winnie and Wipha.

Currently, open source software is the mainstream of numerical modelling in storm surge studies, such as the ADCIRC, FVCOM, and SWAN. Most scholars, through comparison of them in their studies, claim that commercial software (such as the MIKE software), is less precise than the open source software (Strauss et al., 2007; Lin and Fissel, 2014). Admittedly,

30 open source software may achieve a better precision though adjusting the parameters and the algorithms. Results computed in this study by MIKE 21 were in closely agreement with the observed data, and the two-domain, multi-nested TSSM with unstructured mesh has successfully simulated and predicted storm surges generated by typhoon over Shanghai. The computed 
Nat. Hazards Earth Syst. Sci. Discuss., doi:10.5194/nhess-2017-34, 2017

Manuscript under review for journal Nat. Hazards Earth Syst. Sci.

Discussion started: 15 March 2017

(c) Author(s) 2017. CC-BY 3.0 License.

results can be used to provide advice for further coastal planning strategies on the basis of future scenario projections. Therefore, the simulated results using MIKE 21, as a representative of commercial software, is fit for purpose in this study.

Storm surge inundation simulation was conducted within the TSSM; inundation depth and spatial distribution were calculated by this hydrodynamic model. Then the ArcGIS was used to draw inundation maps for the research area. Flood maps drawn in

5 ArcGIS can provide a graphic information with which to analyse the differences in inundation depth from place to place.

\section{Conclusions}

This paper developed an approach for simulating typhoon generated storm surge, which was applicable for coastal mega-cities around the world, even where flood observation data is inadequate. Based on the simulation outputs, typhoon induced storm surge was simulated in Shanghai and inundation maps were drawn in ArcGIS. These maps provide a clearer picture of the

10 spatial distribution and the variation of such vulnerability over Shanghai. Results showed the south of Shanghai, the river banks along the Huangpu and Dazhi Rivers and most of Chongming Island were subject to serious typhoon storm surge inundation. The meso-scale simulation method proposed in this study provides a realistic result at city level. Furthermore, due to its low data and time consumption, this approach can be implemented in a large amount of modelling works. It can be applied to all the coastal cities around the world with insufficient local observed data.

\section{References}

Aerts, J. C., Botzen, W. W., Emanuel, K., Lin, N., De Moel, H. \& Michel-Kerjan, E. O. 2014. Evaluating flood resilience strategies for coastal megacities. Science, 344, 473-475.

Bode, L. \& Hardy, T. A. 1997. Progress and recent developments in storm surge modeling. Journal of Hydraulic Engineering, $123,315-331$.

Butler, T., Altaf, M., Dawson, C., Hoteit, I., Luo, X. \& Mayo, T. 2012. Data assimilation within the advanced circulation (ADCIRC) modeling framework for hurricane storm surge forecasting. Monthly Weather Review, 140, 2215-2231.

Cheung, K., Phadke, A., Wei, Y., Rojas, R., Douyere, Y.-M., Martino, C., Houston, S., Liu, P.-F., Lynett, P. \& Dodd, N. 2003. Modeling of storm-induced coastal flooding for emergency management. Ocean Engineering, 30, 1353-1386.

Choi, B. H., Eum, H. M. \& Woo, S. B. 2003. A synchronously coupled tide-wave-surge model of the Yellow Sea. Coastal Engineering, 47, 381-398.

Davis, J. R., Paramygin, V. A., Forrest, D. \& Sheng, Y. P. 2010. Toward the probabilistic simulation of storm surge and inundation in a limited-resource environment. Monthly Weather Review, 138, 2953-2974.

Dietrich, J. C., Tanaka, S., Westerink, J. J., Dawson, C., Luettich Jr, R., Zijlema, M., Holthuijsen, L. H., Smith, J., Westerink, L. \& Westerink, H. 2012. Performance of the unstructured-mesh, SWAN+ ADCIRC model in computing hurricane waves and surge. Journal of Scientific Computing, 52, 468-497.

Dietrich, J. C., Westerink, J., Kennedy, A., Smith, J., Jensen, R., Zijlema, M., Holthuijsen, L., Dawson, C., Luettich Jr, R. \& Powell, M. 2011a. Hurricane Gustav (2008) waves and storm surge: hindcast, synoptic analysis, and validation in Southern Louisiana. Monthly Weather Review, 139, 2488-2522.

Dietrich, J. C., Zijlema, M., Westerink, J., Holthuijsen, L., Dawson, C., Luettich, R., Jensen, R., Smith, J., Stelling, G. \& Stone, G. 2011b. Modeling hurricane waves and storm surge using integrally-coupled, scalable computations. Coastal Engineering, 58, 45-65.

Dutta, D., Herath, S. \& Musiake, K. 2003. A mathematical model for flood loss estimation. Journal of hydrology, 277, 24-49. 
Nat. Hazards Earth Syst. Sci. Discuss., doi:10.5194/nhess-2017-34, 2017

Manuscript under review for journal Nat. Hazards Earth Syst. Sci.

Discussion started: 15 March 2017

(C) Author(s) 2017. CC-BY 3.0 License.

Natural Hazards
and Earth System
Sciences

Discussions

\section{(c) (i)}

Elsaesser, B., Bell, A., Shannon, N. \& Robinson, C. (eds.) 2010. Storm surge hind-and forecasting using Mike21FMSimulation of surges around the Irish Coast, Copenhagen, Denmark.

Flather, R., Smith, J., Richards, J., Bell, C. \& Blackman, D. 1998. Direct estimates of extreme storm surge elevations from a 40-year numerical model simulation and from observations. The Global Atmosphere and Ocean System, 6, $165-176$.

5 Frazier, T. G., Wood, N., Yarnal, B. \& Bauer, D. H. 2010. Influence of potential sea level rise on societal vulnerability to hurricane storm-surge hazards, Sarasota County, Florida. Applied Geography, 30, 490-505.

Fritz, H. M., Blount, C. D., Albusaidi, F. B. \& Al-Harthy, A. H. M. 2010. Cyclone Gonu storm surge in Oman. Estuarine, Coastal and Shelf Science, 86, 102-106.

Funakoshi, Y., Hagen, S. C. \& Bacopoulos, P. 2008. Coupling of hydrodynamic and wave models: Case study for Hurricane Floyd (1999) hindcast. Journal of waterway, port, coastal, and ocean engineering, 134, 321-335.

Ge, J. 2010. Multi Scale FVCOM Model System for the East China Sea and Changjiang Estuary and Its Applications. Shanghai: East China Normal University.

Ge, J., Ding, P., Chen, C., Hu, S., Fu, G. \& Wu, L. 2013. An integrated East China Sea-Changjiang Estuary model system with aim at resolving multi-scale regional-shelf-estuarine dynamics. Ocean Dynamics, 63, 881-900.

Harper, B. \& Holland, G. An updated parametric model of the tropical cyclone. Proc. 23rd Conf. Hurricanes and Tropical Meteorology, 1999.

Holland, G. J. 1980. An analytic model of the wind and pressure profiles in hurricanes. Monthly weather review, 108, 12121218.

Jakobsen, F. \& Madsen, H. 2004. Comparison and further development of parametric tropical cyclone models for storm surge modelling. Journal of Wind Engineering and Industrial Aerodynamics, 92, 375-391.

Jia, A., Wang, Y. \& Yang, Q. 2011. Research on Inundation Loss Assessment Model for Farmland. Journal of Water Resources and Architectural Engineering, 6, 006.

Jiang, Y., Kirkman, H. \& Hua, A. 2001. Megacity development: managing impacts on marine environments. Ocean \& Coastal Management, 44, 293-318.

25 Lin, Y. \& Fissel, D. B. 2014. High Resolution 3-D Finite-Volume Coastal Ocean Modeling in Lower Campbell River and Discovery Passage, British Columbia, Canada. Journal of Marine Science and Engineering, 2, 209-225.

Lowe, J., Gregory, J. \& Flather, R. 2001. Changes in the occurrence of storm surges around the United Kingdom under a future climate scenario using a dynamic storm surge model driven by the Hadley Centre climate models. Climate dynamics, $18,179-188$.

30 Mcinnes, K., Walsh, K., Hubbert, G. \& Beer, T. 2003. Impact of sea-level rise and storm surges on a coastal community. Natural Hazards, 30, 187-207.

Molteni, F., Buizza, R., Palmer, T. N. \& Petroliagis, T. 1996. The ECMWF ensemble prediction system: Methodology and validation. Quarterly journal of the royal meteorological society, 122, 73-119.

Peng, M., Xie, L. \& Pietrafesa, L. J. 2004. A numerical study of storm surge and inundation in the Croatan-Albemarle-Pamlico Estuary System. Estuarine, Coastal and Shelf Science, 59, 121-137.

Rankine, W. J. M. 1872. A manual of applied mechanics, Charles Griffin and Company.

Savioli, J., Pedersen, C., Szylkarski, S. \& Kerper, D. Modelling the threat of tropical cylone storm tide to the Burdekin Shire, Queensland Australia. Coasts \& Ports 2003 Australasian Conference: Proceedings of the 16th Australasian Coastal and Ocean Engineering Conference, the 9th Australasian Port and Harbour Conference and the Annual New Zealand Coastal Society Conference, 2003. Institution of Engineers, Australia, 285.

Shanghai Municipal Planning and Land \& Resources Administration 2010. Shanghai Master Plan (2010-2030). Shanghai: Shanghai Municipal Planning and Land \& Resources Administration.

Shanghai Nongken Chronicles Compilation Committee 2004. Shanghai Nongken Chronicles, Shanghai, Shanghai Academy of Social Sciences Press.

45 Sheng, Y. P., Zhang, Y. \& Paramygin, V. A. 2010. Simulation of storm surge, wave, and coastal inundation in the Northeastern Gulf of Mexico region during Hurricane Ivan in 2004. Ocean Modelling, 35, 314-331.

Shepard, C. C., Agostini, V. N., Gilmer, B., Allen, T., Stone, J., Brooks, W. \& Beck, M. W. 2012. Assessing future risk: quantifying the effects of sea level rise on storm surge risk for the southern shores of Long Island, New York. Natural Hazards, 60, 727-745.

50 Simmons, A., Uppala, S., Dee, D. \& Kobayashi, S. 2007. ERA-Interim: New ECMWF reanalysis products from 1989 onwards. 
Nat. Hazards Earth Syst. Sci. Discuss., doi:10.5194/nhess-2017-34, 2017

Manuscript under review for journal Nat. Hazards Earth Syst. Sci.

Discussion started: 15 March 2017

(C) Author(s) 2017. CC-BY 3.0 License.

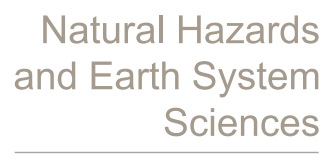

Discussions

(c) (i)

ECMWF newsletter, 110, 25-35.

State Oceanic Administration, P. S. R. O. C. 1989-2015. The oceanic disaster communique of China.

Strauss, D., Mirferendesk, H. \& Tomlinson, R. 2007. Comparison of two wave models for Gold Coast, Australia. Journal of Coastal Research, Special, 312-316.

5 Tan, L., Chen, K., Wang, J. \& Yu, L. 2011. Assessment on storm surge vulnerability of coastal regions during the past twenty years. Scientia Geographica Sinica, 31, 1111-1117.

Timmerman, P. \& White, R. 1997. Megahydropolis: coastal cities in the context of global environmental change. Global Environmental Change, 7, 205-234.

Vickery, P. J., Skerlj, P., Steckley, A. \& Twisdale, L. 2000. Hurricane wind field model for use in hurricane simulations. Journal of Structural Engineering, 126, 1203-1221.

Wamsley, T. V., Cialone, M. A., Smith, J. M., Ebersole, B. A. \& Grzegorzewski, A. S. 2009. Influence of landscape restoration and degradation on storm surge and waves in southern Louisiana. Natural Hazards, 51, 207-224.

Westerink, J. J., Luettich, R. A., Feyen, J. C., Atkinson, J. H., Dawson, C., Roberts, H. J., Powell, M. D., Dunion, J. P., Kubatko, E. J. \& Pourtaheri, H. 2008. A basin-to channel-scale unstructured grid hurricane storm surge model applied to southern Louisiana. Monthly Weather Review, 136, 833-864.

Woodruff, J. D., Irish, J. L. \& Camargo, S. J. 2013. Coastal flooding by tropical cyclones and sea-level rise. Nature, 504, 4452.

Xie, C. 2010. Risk assessment and scenario simulation of storm surge in Shanghai coastal areas. Master Degree in Physical Geography, East China Normal University.

20 Xie, C., Hu, B., Wang, J., Chen, J., Xu, S., Liu, Y. \& Ye, M. 2010. Risk assessment and floodplain scenarios of storm surge of Tianjin Binhai area. Transactions of Oceanology and Limnology, 2, 130-140.

Xie, L., Liu, H. \& Peng, M. 2008. The effect of wave-current interactions on the storm surge and inundation in Charleston Harbor during Hurricane Hugo 1989. Ocean Modelling, 20, 252-269.

Ye, M. 2011. Compounded scenarios simulation and emergency evacuation of storm surge disaster in coastal cities. Doctor of Philosophy, East China Normal University.

Yeung, Y.-M. 2001. Coastal mega-cities in Asia: transformation, sustainability and management. Ocean \& Coastal Management, 44, 319-333.

Yin, J. 2011. Study on the risk assessment of typhoon storm tide in China coastal area. Doctor of Philosophy, East China Normal University.

30 Ying, M., Zhang, W., Yu, H., Lu, X., Feng, J., Fan, Y., Zhu, Y. \& Chen, D. 2014. An overview of the China Meteorological Administration tropical cyclone database. Journal of Atmospheric and Oceanic Technology, 31, $287-301$.

Young, I. \& Sobey, R. 1981. The numerical prediction of tropical cyclone wind-waves, Department of Civil \& Systems Engineering, James Cook University of North Queensland.

Zhang, K., Xiao, C. \& Shen, J. 2008. Comparison of the CEST and SLOSH models for storm surge flooding. Journal of Coastal Research, 489-499.

Zhang, X., Zhang, W., Liu, Y. \& Qiu, S. 2006. Simulation models of flood inundation due to storm tide. Journal of System Simulation, 18, 20-23.

Zheng, L. 2010. Development and application of a numerical model coupling storm surge, tide and wind wave. Doctor of Engineering Doctor of Engineering, Tsinghua University.

Zheng, L., Weisberg, R. H., Huang, Y., Luettich, R. A., Westerink, J. J., Kerr, P. C., Donahue, A. S., Crane, G. \& Akli, L. 2013. Implications from the comparisons between two - and three - dimensional model simulations of the Hurricane Ike storm surge. Journal of Geophysical Research: Oceans, 118, 3350-3369.

Zhu, P., Chen, M., Tao, Z. \& Wang, H. 2002. Numerical simulation of Typhoon Winnie (1997) after landfall. Part I: Model verification and model clouds. Acta Meteor. Sinica, 60, 553-559. 
Nat. Hazards Earth Syst. Sci. Discuss., doi:10.5194/nhess-2017-34, 2017

Manuscript under review for journal Nat. Hazards Earth Syst. Sci.

Discussion started: 15 March 2017

(c) Author(s) 2017. CC-BY 3.0 License.
Natural Hazards and Earth System

Sciences

Discussions

(c) $\underset{\mathrm{Br}}{(\mathrm{i}}$

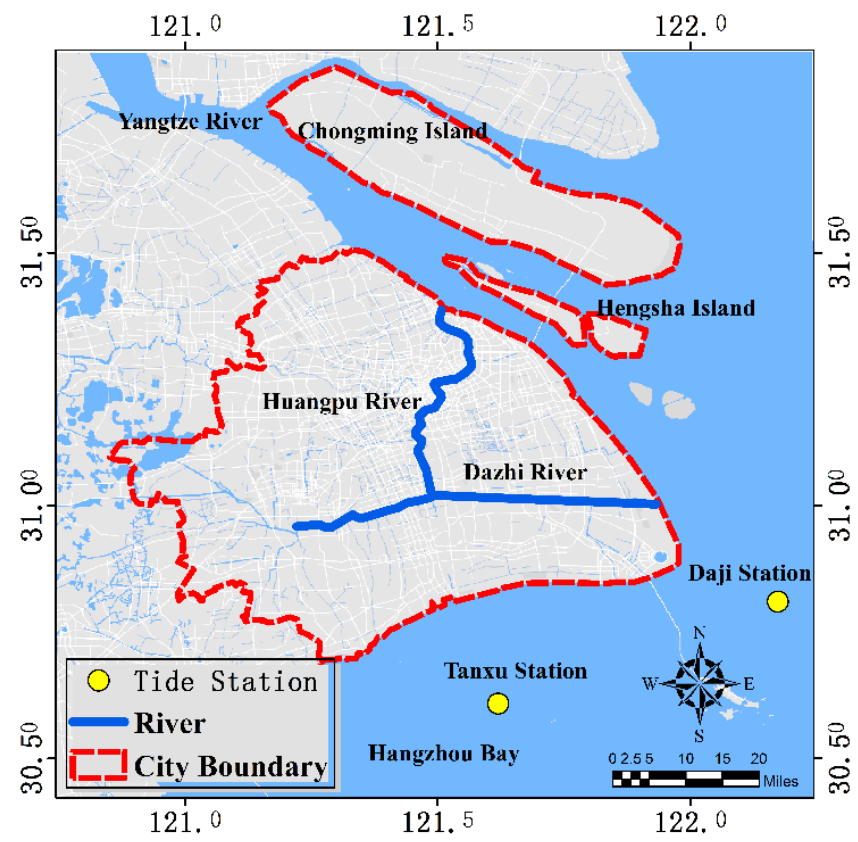

Figure 1: Local map of Shanghai with the red dash line indicating city political boundary and simulation area, while the blue line indicating the Huangpu and Dazhi Rivers. The black points represent two tide gauges used to calibrate models.

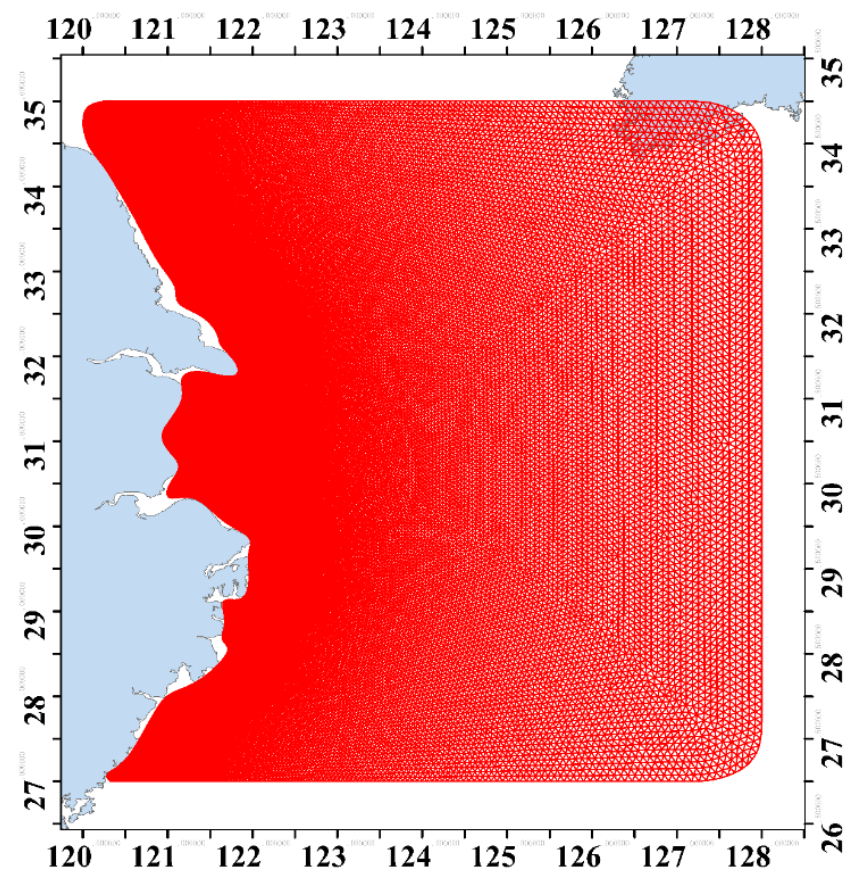

Figure 2: Shanghai Coastal Storm Surge Model with the resolution varying from $10-100 \mathrm{~km}$. 
Nat. Hazards Earth Syst. Sci. Discuss., doi:10.5194/nhess-2017-34, 2017

Manuscript under review for journal Nat. Hazards Earth Syst. Sci.

Discussion started: 15 March 2017

(c) Author(s) 2017. CC-BY 3.0 License.
Natural Hazards and Earth System

Sciences

Discussions

(c) (i)

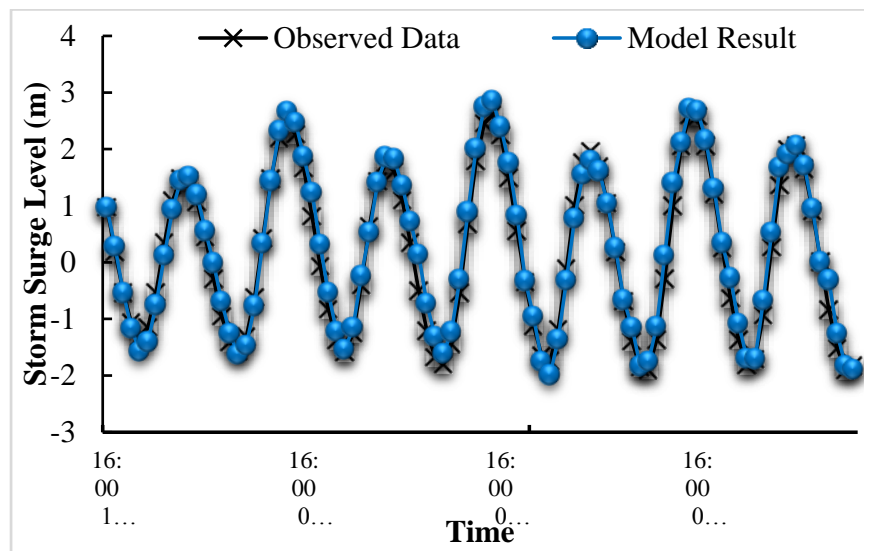

(a) Typhoon Winnie at Daji Station

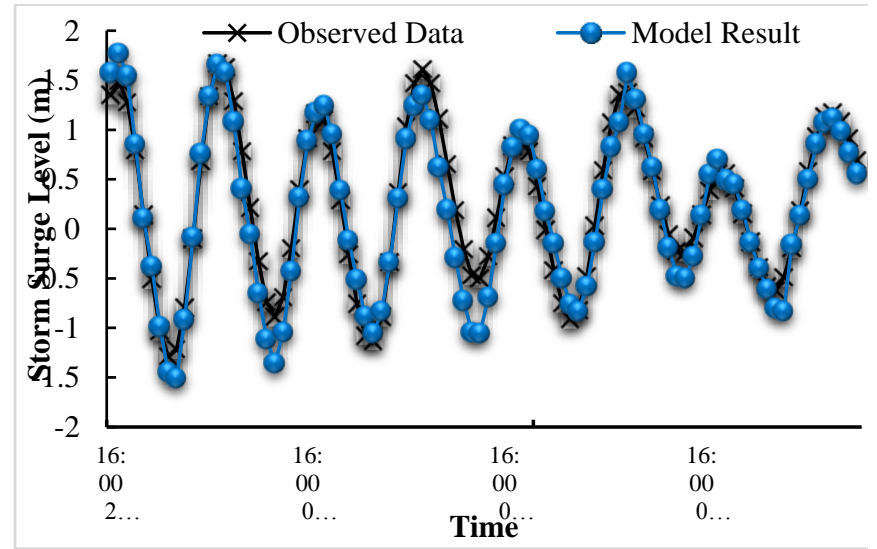

(c) Typhoon Wipha at Daji Station

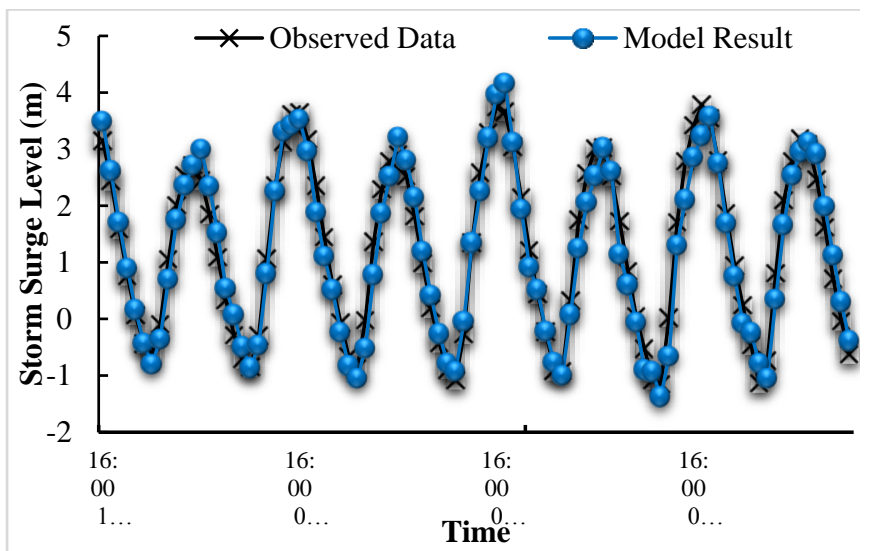

(b) Typhoon Winnie at Tanxu Station

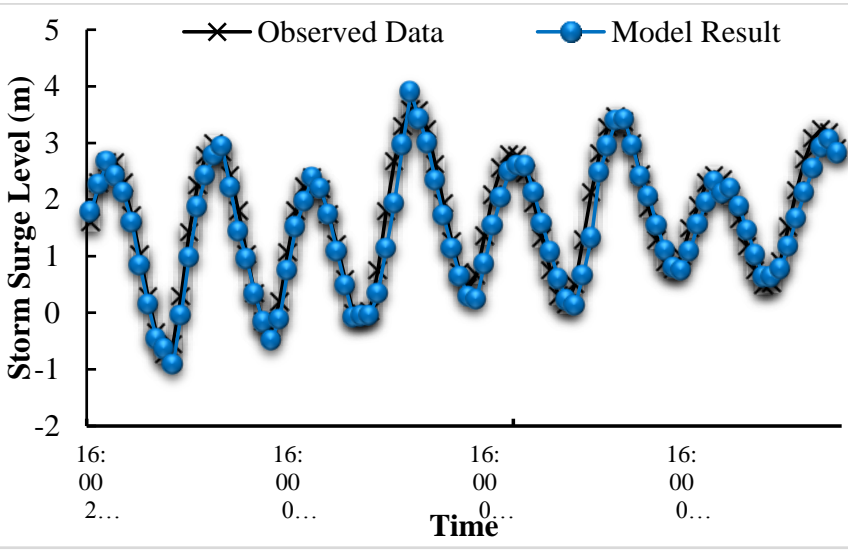

(d) Typhoon Wipha at Tanxu Station

Figure 3: Comparison of the Measurements and Simulated Results of Storm Surge Levels at the Daji and Tanxu Stations Presented in Fig. 1. (a) and (b) present storm surge levels at the Daji and Tanxu Stations during Typhoons Winnie, while (c) and (d) present storm surge levels at the Daji and Tanxu Stations during Wipha after calibration. The blue line indicates the observation data, while the computed results from the SC-TSSM are shown with the red line. 
Nat. Hazards Earth Syst. Sci. Discuss., doi:10.5194/nhess-2017-34, 2017

Manuscript under review for journal Nat. Hazards Earth Syst. Sci.

Discussion started: 15 March 2017

(c) Author(s) 2017. CC-BY 3.0 License.

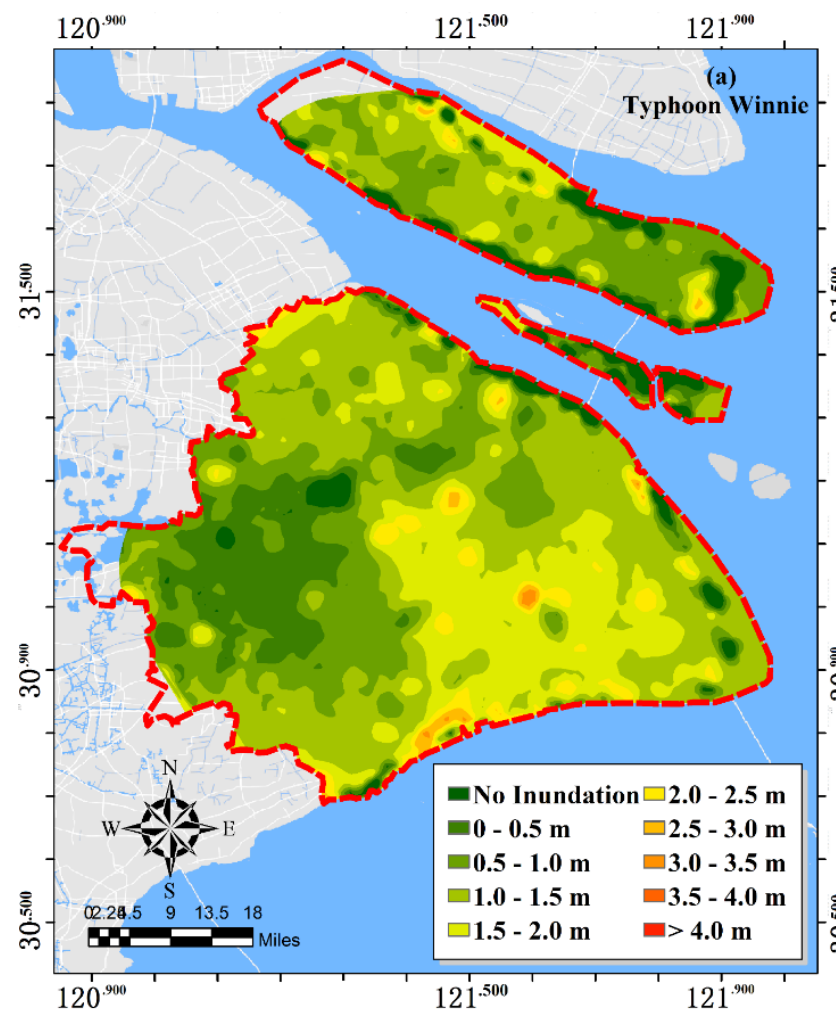

(a)

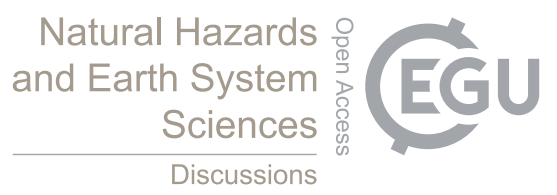

Discussions

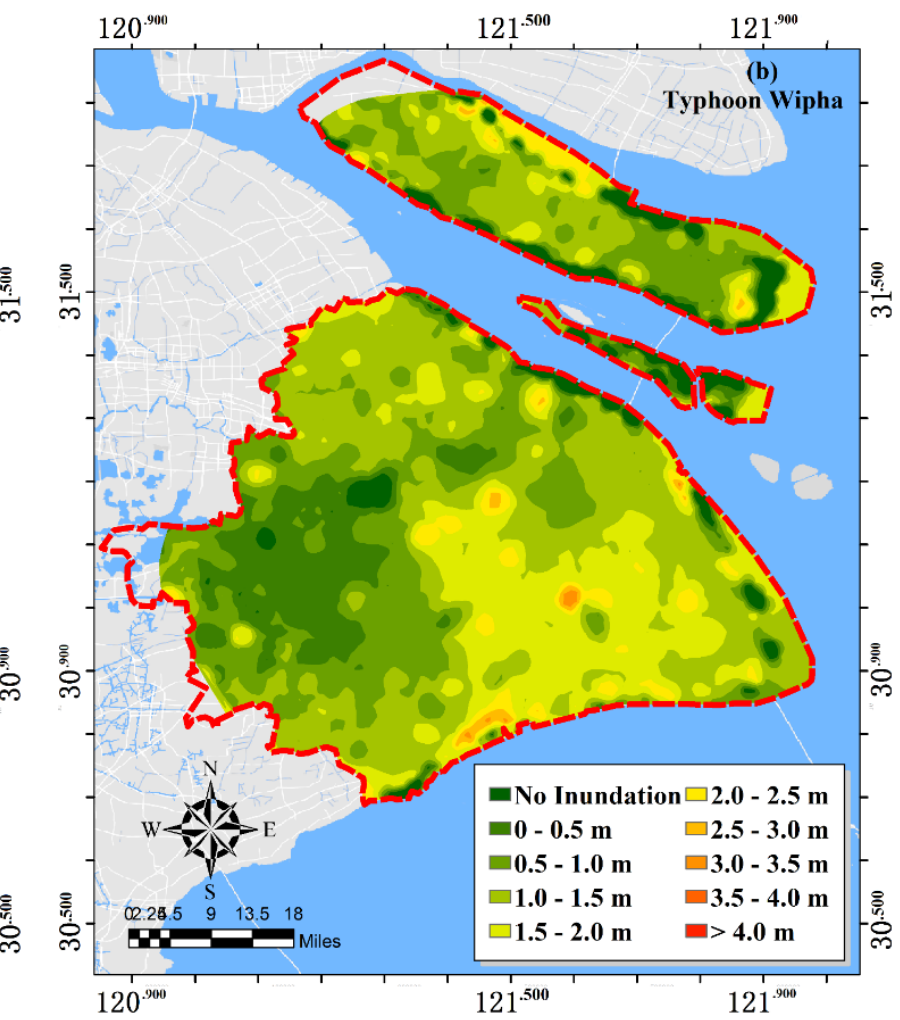

(b)

Figure 4: Distribution of the Maximum Inundation Area and Depth over Shanghai During (a) Typhoon Winnie and (b) Wipha. 